\title{
Uso da proteína total para avaliação da qualidade do colostro bovino
}

Bruno Toledo Silva, Sylvia Marquart Fontes Novo, Stephanie Blima Paulino Leite, Clara Satsuki Mori, Camila Costa Baccili", Natália Meirelles Sobreira, Viviani Gomes

Universidade de São Paulo (USP), São Paulo, SP, Brasil

*Autor correspondente

e-mail: camila.rcosta@usp.br

\section{Resumo}

As imunoglobulinas (Igs) representam 70 a 80\% da fração proteica do colostro, entretanto o teor de proteína total (PT) tem sido negligenciado como parâmetro de qualidade imunológica do colostro bovino. Assim, o objetivo desta pesquisa foi estimar os teores de PT presentes no soro do colostro, comparando-os com os resultados obtidos no refratômetro Brix. Foram obtidas 38 alíquotas do pool de colostro de primeira ordenha de vacas provenientes de fazenda comercial localizada em Araras/SP. A determinação do índice Brix foi feita utilizando-se refratômetro óptico Brix com escala entre 0 a 32\%. Para a determinação dos teores de PT (g/dL), duas técnicas foram utilizadas para a obtenção do soro do colostro: G1- precipitação da caseína (n = 19) e G2 - ultracentrifugação $(n=19)$. Na primeira técnica (G1), as amostras foram centrifugadas (16.000 xg, 15 minutos) para a extração do sobrenadante do colostro. Posteriormente, realizou-se a acidificação da fração líquida com solução de ácido acético (1 Mol/L; pH de 4,5), centrifugação (16.000 xg, 15 minutos) e eliminação da caseína precipitada. 0 pH da fração líquida final foi corrigido com solução de bicarbonato de sódio (1 Mol/L, pH de 6,5). Na segunda técnica (G2), o colostro foi submetido à ultracentrifugação (48.000 xg, 20 minutos). A PT foi mensurada por kit comercial (catálogo TP 4001, Randox ${ }^{\circledR}$ ), em analisador bioquímico (RX Daytona, Randox ${ }^{\circledR}$ ). Todas as amostras de colostro avaliadas apresentaram índice Brix acima de 21\%, indicando qualidade imunológica adequada ( $\operatorname{IgG} \geq 50 \mathrm{mg} / \mathrm{mL}$ ). As medianas obtidas para o índice Brix foram de 29\% (23 - 32\%) no G1 e 28\% (21 - 32\%) no G2 (P = 0,146; teste de Mann-Whitney). 0 valor mediano de PT nas amostras de soro obtidas pela precipitação da caseína (G1) foi de 10,8 g/dL (7,2 - 14,0 g/dL), enquanto que em G2 (ultracentrifugação) foi de 19,4 g/dL (13,9 - 25,2 g/dL). Foi possível observar diferença significativa $(\mathrm{P}=0,00)$, pelo Teste U de Mann-Whitney, entre os valores de PT obtidos nas diferentes técnicas empregadas para a obtenção do soro do colostro. Os índices Brix e teores de PT apresentaram correlação moderada considerando as amostras do G1 ( $\mathrm{r}=0,677$ e P = 0,001) e forte correlação no G2 ( $\mathrm{r}=0,954$ e 
$P=0,000$ ) frente ao teste de correlação de Spearman. Os achados indicam que a diferença obtida entre as técnicas é decorrente da precipitação da caseína, com drástica redução dessa fração proteica no colostro. A escolha da técnica para obtenção da fração líquida do colostro influenciou a sua correlação com os sólidos totais mensurados pelo refratômetro Brix. A extração da caseína provavelmente não reflete nas concentrações de Igs presentes no colostro. Posto isso, estudos futuros deverão ser conduzidos para determinar a influência destas técnicas de separação associadas à mensuração da PT em relação aos teores de Igs do colostro. 